(2) Open Access Full Text Article

\title{
Severe pediatric ocular injury due to explosion of a firecracker inside a soda bottle
}

This article was published in the following Dove Press journal:

Open Access Emergency Medicine

28 October 2010

Number of times this article has been viewed

\section{Tarek A Shazly}

Department of Ophthalmology, Massachusetts Eye and Ear Infirmary, Harvard Medical School, Boston, MA, USA
Correspondence: Tarek A Shazly

20 Pondmeadow Dr Ste 203, Reading,

MA 0I867, USA

$\mathrm{Tel}+\mathrm{I} 78 \mid 3153814$

Fax + I 78I 9429877

Email shazlyt@gmail.com
Abstract: This case report describes a penetrating ocular injury, followed by endophthalmitis, in a four-year-old girl, resulting from explosion of a small K0201 match-cracker inside a soda bottle. The patient presented with two corneal lacerations, ruptured crystalline lens, multiple intraocular foreign bodies, and hyphema of the right eye, for which immediate surgical exploration and repair was performed. The patient developed aggressive endophthalmitis that led to atrophy of the eye within a few weeks. Severe ocular injuries can result from small, relatively "safe" firecrackers. Therefore, this type of firework should not be used, especially by minors.

Keywords: pediatric trauma, endophthalmitis, firecracker

\section{Introduction}

A firecracker is a small explosive device, primarily designed to produce a large amount of noise, and any visual effect is incidental to this goal. Firecrackers are commonly used in celebration of holidays or festivals. According to the US Department of Transportation 1991 classification of dangerous goods, firecrackers are classified as Division 1.4 (Class C) explosives. ${ }^{1}$ This type of firework is ignited by scratching, hence the name match-cracker. Use of this kind of fireworks is legal in many parts of the world, including the US.

Small firecrackers are known to cause burns, abrasion, and multiple foreign body impactions of the lid and cornea, ${ }^{2}$ but not penetrating ocular injuries, especially with the small firecrackers. ${ }^{3}$ To the best of the author's knowledge, this is the first report of a devastating ocular trauma resulting from such a small firecracker.

\section{Case report}

A four-year-old girl presented with lacrimation, photophobia, and blepharospasm two hours following injury to her right eye while playing outdoors with her brother. Visual acuity could not be assessed. Examination revealed two corneal lacerations. The larger one was $6 \mathrm{~mm}$ long, extending from the apex of the cornea to the superior-temporal limbus. The smaller one was a $2 \mathrm{~mm}$ laceration, $1 \mathrm{~mm}$ anterior and parallel to the 12 o'clock limbus. The iris prolapsed through the larger corneal laceration, with partial hyphema, and a ruptured crystalline lens. A B-scan ultrasound showed an intravitreal foreign body, and a computed tomography scan confirmed its presence, along with another intralenticular foreign body.

The patient underwent immediate surgical repair of the corneal wounds using interrupted 10/0 nylon sutures, irrigation/aspiration of the blood and lens matter 
from the anterior chamber, and extraction of a $5 \times 2 \mathrm{~mm}$ intralenticular glass chip.

By the end of the surgical repair, a less than $1 \mathrm{~mm}$ glass foreign body was visualized in the posterior third of the vitreous inferior to the macula. Given the inert nature of the foreign body, lack of any signs of endophthalmitis, and the limited visibility due to edema around the corneal lacerations, it was preferred not to do an immediate vitrectomy.

On the second day, the anterior chamber was full of hypopyon, and the cornea was edematous (Figure 1). A B-scan showed moderate amplitude echoes all over the vitreous cavity.

After drawing a purulent vitreous sample, vancomycin $1 \mathrm{mg} / 0.1 \mathrm{~mL}$ and amikacin $0.4 \mathrm{mg} / 0.1 \mathrm{~mL}$ were slowly injected into the vitreous cavity. Topical gatifloxacin $(0.3 \%)$ and prednisolone acetate (1\%) were used hourly, and atropine sulphate $(1 \%)$ was used twice daily. By the next day, the cornea started to melt down, and wounds started to gape despite the treatment.

Culture and sensitivity revealed Staphylococcus aureus sensitive to vancomycin. Intravitreal injection of vancomycin and amikacin was repeated, with no improvement. During the following weeks the inflammation subsided, and the eye ultimately atrophied over the following months.

\section{Discussion}

Careful questioning revealed that the patient's unsupervised eight-year-old brother had ignited a small K0201 firecracker, put it in an empty glass soda bottle, and then threw it away. This innovative way of using firecrackers converted a relatively

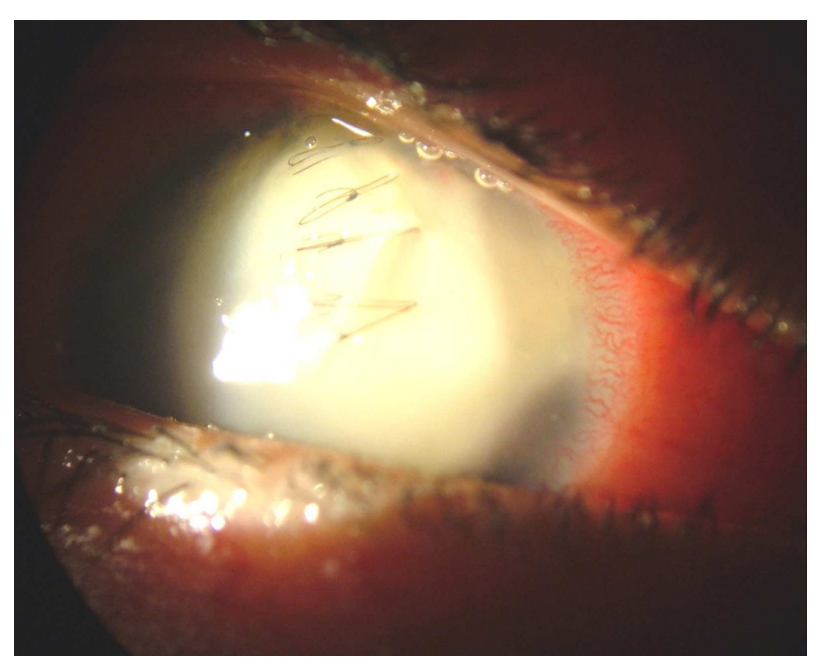

Figure I Day two following the trauma. The eye was injected, the cornea was edematous with dehiscence of the corneal wound, and the anterior chamber was full of hypopion. safe explosive into a grenade. The enormous volume of gases produced on combustion of the firecracker powder caused the bottle to explode, with numerous flying glass fragments. Unlike a metallic grenade, in which the flying fragments tend to be very hot and sterile, an exploding glass bottle produces cold, potentially infected flying fragments, which adds risk of infection to the mechanical trauma.

Although there is no clear consensus regarding the use of broad-spectrum parenteral antibiotics in the treatment of endophthalmitis following traumatic injuries of the eye, many clinicians follow the Endophthalmitis Vitrectomy Study guidelines by using intravitreal injection without parenteral or periocular antibiotics for patients with hand motion or better vision. ${ }^{4}$ More aggressive treatment, including early vitrectomy, has been recommended, because of the more virulent nature of causative organisms involved in post-traumatic endophthalmitis compared with organisms causing postcataract surgery endophthalmitis. ${ }^{5}$

Unusual causes of ocular injuries are encountered in developing countries. Injuries due to chemicals, cigarettes, and medical syringes have been reported. ${ }^{6,7}$ Lack of strict regulations controlling access of children to these hazardous materials leads to disastrous visual outcomes in young children every year. ${ }^{3}$

In this case report, it is emphasized that even the smaller low-energy firecrackers that are supposed to be safe can result in severe ocular injuries and loss of vision. More strict regulations should be applied to these types of explosives.

\section{Conclusion}

Firecrackers are commonly used in celebration of festivals. Small firecrackers can cause burns and abrasion of the lid and cornea, but not penetrating ocular injuries. To the best of the author's knowledge, this is the first report of a devastating ocular trauma resulting from such a small and "safe" firecracker.

\section{Disclosure}

The author reports no conflict of interest in this work.

\section{References}

1. Office of Hazardous Materials Safety, U S. Department of Transportation. Available at: http://hazmat.dot.gov/sp_app/approvals/approvals.htm\#class. Accessed 2010 Oct 1.

2. Wilson RS. Ocular fireworks injuries and blindness. An analysis of 154 cases and a three-state survey comparing the effectiveness of model law regulation. Ophthalmology. 1982;89(4):291-297.

3. Jaison SG, Silas SE, Daniel R, Chopra SK. A review of childhood admission with perforating ocular injuries in a hospital in north-west India. Indian J Ophthalmol. 1994;42(4):199-201. 
4. Endophthalmitis Vitrectomy Study Group. Results of Endophthalmitis Vitrectomy Study: A randomized trial of immediate vitrectomy and of intravenous antibiotics for the treatment of postoperative bacterial endophthalmitis. Arch Ophthalmol. 1995;113(12):1479-1496.

5. Han DP, Wisniewski SR, Wilson LA, et al. Spectrum and susceptibilities of microbiologic isolates in the endophthalmitis vitrectomy study. Am J Ophthalmol. 1996;122(1):1-17.
6. Serrano JC, Chalela P, Arias JD. Epidemiology of childhood ocular trauma in a northeastern Colombian region. Arch Ophthalmol. 2003; 121(10):1439-1445.

7. Hussainy AK, Shazly TA. Severe ocular injuries from improperly disposed medical syringes in children. J Pediatr Ophthalmol Strabismus. 2010;47(2):108-110.

\section{Publish your work in this journal}

Open Access Emergency Medicine is an international, peer-reviewed, open access journal publishing original research, reports, editorials, reviews and commentaries on all aspects of emergency medicine. The manuscript management system is completely online and includes a very quick and fair peer-review system, which is all easy to use.

\section{Dovepress}

Visit http://www.dovepress.com/testimonials.php to read real quotes from published authors. 